\title{
THE GENERALITY AND IDIOSYNCRASY OF VERB FORMATION IN MADURESE LANGUAGE
}

\author{
Mohammad Halili \\ Universitas Trunojoyo Madura \\ mohammad.halili@trunojoyo.ac.id
}

\begin{abstract}
The current research aims at scrutinizing the generality and idiosyncrasy of verb formation mirrorred in Madurese language. The language has been easily understood and intuitively acknowledged for native speakers. Since the (ir)regularity-changing a word in shapes and functions-also demonstrates its linguistic facet, the approach from morphological explanation becomes crucial. This is to provide background information for those especially interesting in learning the language and or simply making even the native speakers aware of. Furthermore, it would be beneficial in a way that the proper uses both syntactically and semantically are appropriate. This paper is an explanatory research from which the the data are collected from WhatsApp (WA) group chat. All members are indigenous Madurese. Thus, the group facilitates the extensive use of the given language. By identifying, capturing and classifying the required data, the messages sent through the group were subsequently analyzed from the proposing morphological underpinnings. The findings of this research demonstrate that prefix $a$ - and $-e$ are considered to be bound morphemes as they cannot stand alone. They function to form a verb in active voice and a verb in passive voice. The generality takes place. The idiosyncrasy is, however, also phenomenal.
\end{abstract}

Keywords: morpheme; idiosyncrasy; Madurese language; regularity

\section{INTRODUCTION}

Morphological processes of languages vary considerably based on their syntactical context, so does Madurese language. It has been clear that the word formation is changing due to syntactical context. It can be indicated by the changes of the word class due to grammatical requirement to function properly. But some may be misleading in use due to inappropriate word forms. The current research is thus mainly concerned about the regularity and idiosyncrasy of verb formation as a result of morphological process in Madurese language. 
Apart of definition, verb can mean many things to readers. It can be a word describing an action or might be simply positioned after the subject of the sentence. It is to further explain what the doer of the sentence does. For instance, the word class of word take is fallen into verb, as a dictionary indicates. On the one hand, taking is also known to be verb. The main issue is that how the given word would be different in terms of use and function. Particularly paying attention to the latter one, it is generally accepted to say that the base of the taking is take. One may be aware of the additional suffix -ing. So, the general idea of the discussion shows to how we are able to identify the contributing elements to the word shapes and their functions.

Referring to take and taking exemplified above, affixation occurs. Suffix -ing attached to taking cannot stand alone but indeed carries its own meaning. The suffix is syntactically required to sense the use of the word. For example, "The tests take 60 minutes." and "Many students are taking extra time course during the holiday." are two instances of the analyzed words behaving differently. It can be understood that take behaves in that way linguistically simply because the tense of the sentence is present tense. The verb must be in the form of V1 (take). However, taking, in the second sentence, has been suffixed by -ing due to grammatical aspect ask to do so. The tense of the sentence is present continuous tense. Therefore, suffix -ing presents. Take is free morpheme and -ing is bound morpheme.

The morphological process such as how verbs are formed is applicable indeed to any languages. What occurs in English language may be simply practical in nature to other languages. Madurese language is unexceptional. It shows morphological process as well to meet both grammatical and semantic aspects of the language.

Research focusing on morphological aspects of languages appears to be numerous. A number of research focusing on the morphological issues can be said to have serious attention particularly from linguists. Bolozky (1982) for instance, studied the Modern Hebrew verb formation. Accordingly, semantic is an essential issue in canonical morphological forms in the verb system. The major discussion was about the debate of the notion between transitive and intransitive verbs in causation, agency, and activity. It is, however, concerned about agentive and nonagentive ones. Causative agentives tend to be assigned to hif'il and noncausative agentives to pi'el.

$\mathrm{Wu}$ and Palmer (1994) also did the research on the similar discussion. Their main focus was on the semantic representation of verbs in computer system and how they affect lexical selection problems in machine translation (MT). The research employed the scheme knowledge-based MT approach. It pointed out that examples and experimental results indicated that inexact matches can achieve correct lexical selection.

Studies investigating Madurese language from morphological process, however, seem rare to find. Research on the given language may have been undertaken, but appears inadequately addressed. Ghofur (2008) took a look at both similarities and differences between Madurese language and English language from morphological perspectives. Accordingly, both languages demonstrate the same morphological system. Specifically, 
Madurese language indicates such morphological process due to syntactical contexts as English does.

Azhar (2011) also studied the verbs in Madurese language. He elaborates the variations on verb organization. He presents the verb classification of Madurese language in three clusters: verba pangkal (base form of verb) or verba pangkal terikat (bound base form of verb), verba asal (root verb) or verba dasar bebas (free base of verb), dan verba turunan (derivational verb). The example of base form of verb are eret (pull) and pele (choose). Elang (lose) and daddhi (become) are for free base form of verb. Ajalan (run) and akalambi (to cloth) are for derivational verb. The last notion is in line with the idea of bound morpheme to which prefixes or suffixes are applicable.

Compared and contrasted the current investigation with the previous research, it can be found a number of similarities and differences. One of the facts indicating their similarity is that they share the similar notion on the issue of morphological process and precise verb organization, as the main idea of the discussion. In contrast, they are distinct in some ways. Ghofur (2008) pointed out that morphological process of Madurese and English language is the same. They show their own morphological processes in each context.

Azhar (2018) largely presents the variation of verb formation in Madurese language. But none, either Ghofur (2008) or Azhar (2011) discusses the word and its forms: shapes and meanings. It means that regularity and idiosyncrasy is widely discussed in the current context. For that reason, this study plays a significant role to widen academic perspectives to the issue at hand. Therefore, this is essential to be studied.

\section{THEORETICAL FRAMEWORK}

\section{Free and Bound Morpheme}

Semantic needs sentences. It means that word forms must be in line with grammatical patterns of the language. The ideas of free and bound morphemes are closely related to whether morphemes can stand alone or whether they must be attached to a base morpheme (Fromkin, Rodman, \& Hyams, 2011). Morpheme that can stand alone is like close and open. The given words carry their own meaning and are free to be attached by prefixes and suffixes. Closed and reopen are bound morphemes. The suffix -ed and prefix re-absolutely cannot be independent. It is understood that their existences are meaningful. But it should be noted that they work properly when they are attached to the other morpheme. Suffix -ed in closed can indicate stative passive. Meanwhile, the prefix -re means repeated action. Following are the examples to make the idea clearer:

a. The shop is closed.

b. The police reopen the case.

From the explanation above, we can understand the notion how free and bound morpheme in nature. The morphemes deal with the function of prefixes and suffixes, and infixes which is relevant as well as contribute to the change of the word classes and 
meaning of the words. They shed light on their application in a proper context and explain how grammatical aspect of a sentence should be put into account with semantic features.

However, in some ways, the morphological processes vary from one context to the other. The exemplified cases should be reckoned as normal patterns in English. But should they not be taken for granted simply because, in some cases, the given morphemes work in that way naturally. The word repeat for instance, does not consist of smaller part of morpheme. It means that re does not mean that it is a prefix, morpheme attached to peat. English does not acknowledge the re-peat as comprising to smaller unit of the words that can be broken down into a meaningful morpheme. Therefore, it is beneficial to acquire the idea of regular and irregular inflection as explained below.

\section{REGULAR AND IRREGULAR INFLECTION}

Regular and irregular inflection deal with the idea of either a word will have the same productivity both in shapes and meaning or not. It can be said that a word has regular inflection when it has the same form, for instance, by adding -s or -es (work works, watch - watches) to show plural form. In contrast, a word is said to be irregular when it has different form of plural concept. The examples for that are man and women. A man is a singular form. To form its plural form cannot simply by adding suffix $-\mathrm{s}$ at the end of the word; mans. English does not acknowledge this sort of concept. The plural form of man is men.

At the same point, womans is also not acknowledged in English version. It does not state the plural form of the word. The plural form of woman is women. The novice learners of English may employ the general ways of forming plural noun in English by adding suffix $-s$ and $-e s$ at the end of the words. For that reason, some words in English should be listed in dictionaries since the forms are unpredictable.

The notion of regular and irregular forms can be applied in the contextual issues discussed. The particular issues studies are related to how verbs, both in active and passive voices, are formed in Madurese language. The following explanation reckons Madurese language in general and verb organization as a result of morphological process due to grammatical and semantic requirement.

\section{Madurese Language and Verb Organization}

Madurese language is spoken mostly throughout the Madura Island, consisting of four administrative regencies. They are Bangkalan, Sampang, Pamekasan, and Sumenep. Acroos all varieties, Madurese is an SVO language (Jeoung, 2016). The following part explains the verb formation in Madurese language.

\section{Verbal Morphology}

According to Davies (2010), one of the most salient properties of Madurese morphology is the voice system - morphology that indicates the relationship of thematic roles and grammatical functions. One of its forms can refer to the actor voice $a$-. 
Accordingly, the actor voice prefix $a$ - works in the same way as ng- to derive verbs in the actor voice. Many active intransitive and some active transitive verbs roots take $a$ - $a$ s prefix.

$\begin{array}{ll}\text { Berri' (give) }^{\prime} & \text { aberri' } \\ \text { Pasa (fast) } & \text { apasa } \\ \text { Ghelle' (laugh) } & \text { aghelle' } \\ \text { Remo (party) } & \text { aremo }\end{array}$

Another actor voice is prefix $n g$-. It functions to form verb. It signals the active voice verbs and is directly affixed to the root. Davies (2010) states that the prefix $n g$ - and its morphophonological variants, signal actor voice or active voice verbs and they are used when the actor is the subject of the sentence. It is affixed directly to verb roots as exemplified below:

$\begin{array}{ll}\text { Ngénum (drink) } & \text { énum } \\ \text { Ngare' (cut the grass with scythe) } & \text { are' }^{\prime} \\ \text { Ngala' (take) } & \text { kala' }^{\prime} \\ \text { Ngakoh (acknowledge) } & \text { akoh }\end{array}$

Verbal morphology in Madurese language also deals with the objective voice. It is closely related to the use of prefix $e$-. Davies (2010) asserts that the prefix $e$ - can be affixed to any transitive verbal stem to signal that an object has been selected as subject. It has been frequently claimed to be equal to passiveness. The examples are:

$\begin{array}{ll}\text { Ekakan (eaten) } & \text { kakan } \\ \text { Etoles (written) } & \text { toles } \\ \text { Ejual (sold) } & \text { jual }\end{array}$

Ekerem (sent) kerem

The given examples show the affixation in Madurese language. Based on Davies (2010), Madurese affixation includes prefixes, suffixes, circumfixes, and very limited infixation, alongside from reduplication. Those are, of course, the confined varieties due to the need of analysis and to maintain the primary focus of the study.

\section{METHOD}

This research utilized the explanatory approach instead of dealing with statistical or numerical data. In other words, the research presents the data and data analysis in the form of words and has nothing to do with numbers as the main discussion.

The source of the data is WhatsApp (WA) group of MTsN 97 SUMPA KERONG ONGGHU. All the participants are Islamic Junior High School-called MTsN-alumni graduated at 1997. The school is located in Sumber Bungur, Pakong, Pamekasan, Madura. The reason for this choice is that the group facilitates the active use of Madurese language 
rather than other languages such as Javanese and Bahasa Indonesia, even though most of the member are bilingual

The data deal with regularity and idiosyncrasy. The chosen verbs have prefix $a$ - and $e$-. They show the bound morpheme marking the activities in active and passive voices. The following diagram illustrates on how the data collected.

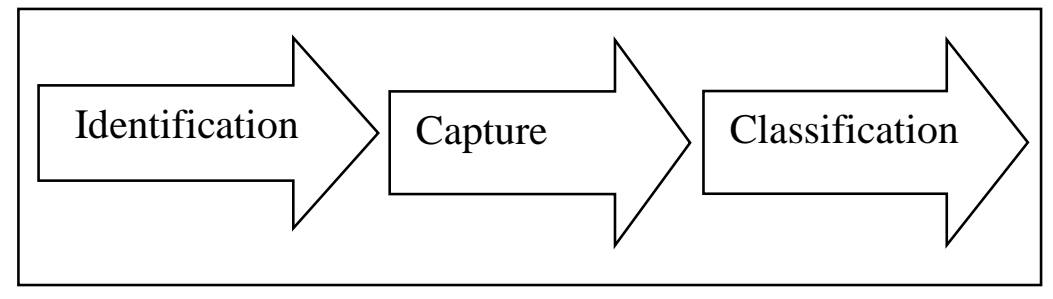

Figure1: Data collection steps

First, the researcher identified the potential data. Since tremendous data present, the data was mainly focused on the structure of the verbs, instead of other forms of word classes appear on the screen. The identification was based on the texts consisting of both regular and irregular verb formation.

Following the steps, the data was captured by using the screenshot features available on the phone so that the data can be referred swiftly upon analyzed. It is a simple technique to picture the text by going to device button, click more menu, and screenshot presents. The screenshotted data will be automatically saved on photos on the main menu on the phone. All screenshot data will be recalled effectively when they are required.

Finally, the data was classified based on the type of verb structures. From the very beginning, we alerted to stick on the data needed. So that any data related to verb formation of the language were classified. The approach was helpful in analyzing the data since the focus of the investigation was divided into two parts: the prefixes $a$ - and $e$-. The classification makes the order of the analysis easy to be arranged logically.

Since the relevant data had been categorized and sorted, the data were analyzed as follows. Selecting the conversation, screenshotting the utterances, and analyzing the chosen data. First, the researcher selected only relevant data to the investigation. Unnecessary data was eliminated, while the required data were screen-shootted. It had been done to guard them from loss as to arrange them in order way. Finally, the chosen data was scrutinized. In this stage, we examined how the speaking data and proposing theories are interwoven.

\section{FINDINGS AND DICUSSION}

This part discusses the morphological process of verb formation in Madurese language. It consists of two parts: prefix $a$ - and $n g$-. Each idea explained in the following section: 


\section{Prefix $a-$}

The main concern of this part is the prefix $a$-. The selected data and their analysis presents below:

1. Kok mareh tedung.. (I just wake up.)

2. Kik ajegeh sound brow ad acara timangan (I am keeping the sound system, brother. We have timangan ceremony at the moment.)

5. Oooo... (Oooo.. (exclamation))

Bunter brow (round, brother)

7. Eee....(eee....)

The italic word, line 2 (ajegeh) refers to the verb of Madurese language. The prefix $a$ - indicates in which the base is jegeh. It can be literally translated into English as keep. Prefix $a$ - in this context functions as a verb maker. It should behave linguistically in this way for grammatical needs. Ajegeh acts as verb of the sentence. If there is no change from noun to verb by adding the prefix $a$-, the sentence may not make sense because jegeh is a noun, not a verb. Therefore, the prefix $a$-is needed to meet the grammatical requirement and semantically appropriate.

The context of the conversation is all about joke pertaining to Thursday night. It has been culturally believed that making love, with legal partner, at the given night is seen to be religious suggested. Based on the conversation, however, the participant cannot achieve the intended 'game' because they are on duty still (taking care of sound system). Therefore, the joke that is intended to the participant seems to be going out of reach. The following data also indicates the verb formation in Madurese language as transcribed below:

8. Engkok tak soghi nis tp sengkah se nyapa ah ka been sateya mun tak lem e nyareyakin rebbung $(-) ;(;)$ (I am not rich but reluctant to ask since you do mind giving me rebung (young bamboo.))

12. Mon been mon dunxah sogi sarah keng gun syang tak kem abiniah ... todus se aberrieh mon gun rebbung $(;)(-) ;()$ (you are rich but single... I am shameful to give you rebung.)

15. Gi' tak musem... mon la abiniah e ngibeaginah makeh sa sak bulog (it is not harvest season.. if you are getting married, I'll give you a lot.)

The italic word, aberrieh, line 13 is a verb, meaning give. Prefix $a$-functions to form verb from the root of berri'. It behaves linguistically this way because of the grammatical requirement of the sentence. Prefix $a$-is indeed the bound morpheme which does not carry meaning when it is not attached to the root of berri'. Because it attaches to the root berri', it then becomes meaningful. Therefore, prefix $a$ - is required to make not only the word meaningful, but also semantically appropriate.

Looking at the conversation, we can identify the context of the text. The main issue being discussed is marriage and gift topic. One of participants (8) wishes to have rebbung, 
young and eatable bamboo to other participant. However, the interlocutor (12) is getting reluctant to give it because the previous participant (has not married yet. However, the next participant (15) has no problem to send a bug of rebbung to the participant 1 if they got married. If we have a look on the emoticon used, the issue was delivered in a humorous sense.

The following data also demonstrates the verb process of Madurese language:

16. Dinah ram am... kor orengah tak ekelonyut .. (That's fine, Ram. The guy is not stolen, more important.)

18. Mon e group reah engkok $\mathrm{k}$ wsil tak abesah ben tak manggil lora topeh mon katemmoh ben orengah engkok beradab manggil lora wasil ben aponcaepon ... beda pole mon $\mathrm{k}$ dhani engkok mon katemmon langsung aorak sakellarah. (I did not call Wasil as a lora, social naming to the son of the priest. But I do when I meet in person. In contrast, I called Dhani loudly when we meet.)

The italic word, aorak, line 21 means called loudly. As shown in previous paragraph, it also indicates the same phenomenon of verb process occurs in Madurese language. It is generally accepted to have verb form from noun, we add prefix $a-$. Aorak meaning shout is a morphological process to which prefix $a$-functions as a bound morpheme. It means that the given prefix cannot stand alone and it carries meaning when it is attached to the root of the words. However, if the prefix $a$ - is meaningless when it stands alone.

The context of the conversation refers to the social marker. Culturally, the son of the Kyai (Islamic priest) will be called as lora. It aims to show deference to their social position as the knowledgeable member of the society in particular Islamic sciences. Based on the text, we can see how the participant (18) does not show loyalty to some extent to the given social consensus. In one situation, the participant shows their respect by calling lora when they meet with Wasil (name of the members) in person. However, they show different linguistic behavior when they are talking on line.

The following data shows phenomenon alike.

24. Abbe mon ben mored tak acaca ron sakaron ... axaxi ben tepuk tangan jek reng paud ... taiye dhan ... Dhani jieh ka sarjana ngabik 2. (The students dont talk rubbish. They sing and clap as pre-school aged children do. Is it right, Dan?

Danni has two academic qualification.)

The utterance consists of two italic words as data: acaca and axaxi (line 24). Acaca means talk. Axaxi means sing. Starting from the first one, acaca. Its root is caca. It functions as a verb after attached the prefix $a$-, meeting the grammatical requirement. This is because the position of acaca in the sentence is a verb. It needs to be adjusted to have proper semantic and syntactical aspects. The subject of the verb is 'hidden'. This is what we called elliptical sentence. In other words, the subject of the sentences is not definitely stated. The interlocutor, however, mutually understand who is doing the action. Therefore, it can be considered not to reduce the syntactical elements of the sentence since the speaker and listener mutually understand. 
The second chosen data was axaxi, sing. Prefix $a$ - makes the word class of xaxi changes. The change occurs from noun to verb. It works in this way because the word's position is the verb of the sentence. Therefore, it should be adjusted to the need of grammatical aspect of the sentence.

The context of the conversation indicates the linguistic manners among students and teachers in classroom setting. The speaker shows that they speak properly when they are talking to their students. In addition, they sing along and clap with the students because they were teaching pre-school aged students. It also indicates that one of the participants, names Dhani is able to finish his degree, both graduate and master degree.

The data demonstrate the strong evidence of regularity of verb formation as a result of prefix $a$ - occurs in Madurese language. It means that the meaning of prefix $a$ - is consistent. The given prefix will carry a certain meaning unless attached to the base of the words. Therefore, it is classified to be a bound morpheme, morpheme that cannot stand alone, but should attach to other morpheme to be meaningful.

\section{Prefix $e$ -}

Prefix $e$ - functions to transform the active form to passive one. The following data shows the verb process to meet the grammatical aspect.

29. Mon k sengkok tak loppah ra.? (You don't forget me?)

30. Mun been makeh tak a krim foto jhet la etemmuh jhek reng mor leke ... (:) ;) (;)

(:) (you are easily identified even without picture that you are from river east.)

The data is etemmuh (line 30). It means identified (passive voice). Prefix $e$ - is to make the grammatical change from active to passive form. It meets the need of grammatical functions of the sentence. The root of the word is temmuh (identify). However, the class of the words must be altered to passive form by adding the prefix $e^{-}$. Therefore, the word (etemmuh) suits grammatical and semantic aspects.

The contextual of the conversation is about the memory of the face. It can be understood as it has been for years that the members of the group live their own, stay apart one to others. The participant 29 asked the participant 30 whether the participant 29 forgot their face or not. The 30's response shows that that they can identify the required information even though they do not share photograph in the group.

33. Tepi gendong anak Risatul laili (You carry Risalatul Laili's daughter.)

35. Abbu ra di mik ekeremin tuyl ben di sengkon (Di, stop talking. Nevertheless, I'll send you Tuyul (traditionally, magic creature.))

38. Tuyul

39. Iye.. pola mik loppah roah (Yes, in case you might forget.)

The above transcription indicates one of the italic word showing passive form of the verb; ekeremin. It means send. The sentence requires the proper verbs to make the sentence make sense both grammatically and semantically. The root of the word is kerem, meaning send. Just because the subject of the sentence in the active form becomes object in the passive voice, so do the verb. In English, the main verb of the sentence in the active voice 
changes to verb past participle (V3) in passive voice by including to be. In Madurese language, it shows different process: the prefix $e$ - is and suffix -in added. Respecting the rules, kerem becomes ekeremin.

The context of the text is that the speakers, just like the previous data, chatted the idea whether the members of the group remember or forget about their faces. It may not be a concern to remember one's name, but it concerns whether they still remember their face or not as their Junior High School friends. Accordingly, they will be sent tuyul to help them to remember their face upon they forget.

40. Iye.. pola mik loppah roah (Yes, if you forgot.)

41. Tak kerah lupa mun ka been nis.. apapole sampe tapapak ktemu, been mau berangkat kik ada dirmahx ja la ekeding baunah ka bere. (It is downward impossible to forget you, Nis. Especially when we meet, your aroma has been smelled even though you are still at home).

46. Ha .. ha .. mak abit ak nemmoneh apecet ..(haha. I dont see you to get massage for so long.)

The above transcription is another data relating to the prefix $e$ - to form passive voice. It can be seen from the data, ekeding, line 42 meaning smelled. The root of ekeding is ngideng. The word class changes due to grammatical requirement to have a passive voice. Therefore, the verb form, from ngiding, should be adjusted to ekeding. This is the regular form in which the prefix $e$ - is a passive maker.

The context is, again, about the issue of remembrance of the members' face. Accordingly, the participant 40 did not forget their faces. When they were leaving (to school), the smell of the speaker 40 can be identified.

However, it should be noted that not all prefix $e$-functions as to change word function from active to passive one. On the other way, $e$ - is in nature the form of the root. It can be exemplified from the following extract.

48. Tong ebeng fid .. jieh ka elang tepaen ngennyot jieh (we share one by one, Fid. It loses.)

50. Soro onlaon niss.. tako' tasernak (ask them to swallow slowly or goes wrong)

52. Mon ghun tasernak tak rapah. Takok coto. (Going wrong is no problem. But no broken).

If we pay attention the utterance from the speaker 48, two italic words available. Ebeng means one by one and elang means lose. The two chosen data indicate to have $e$ - as initial word. However, it does not mean an affixation or prefix. It indeed is the nature of the word which initiated by the letter $e$. Therefore, it can be said that not all $e$-functions as prefix, to change active to passive form. It indeed show such idiosyncrasy in Madurese language.

The above evidence apparently indicates such irregularities or idiosyncrasy in Madurese language. Prefix $e$ - can function to make change from active to passive form to meet grammatical aspect. However, not all $e$ - is equivalent to prefix. The words are in nature initiated by the letter $e$-. 


\section{CONCLUSION}

The main concern of this research is to look at the verb formation of Madurese language. It has been the main issue because the research focusing on the given topic appears to have few attentions. As other languages such as English, Madurese language also shows the morphological process due to the grammatical or syntactical requirement. The current investigation is thus interesting to reveal how regularity and idiosyncrasy of verb formation are phenomenal in Madurese language.

This study shows that prefix a- and e- has contribution to the change of the words in its shape and function. In this context, both carry morphological process to form verb and change the voice of the sentence. Based on the analysis, they show such regularity in a number of cases.

However, it is important to keep in mind that not all words initiated by $e$-indicate the passive form. In some ways, they are the nature of the word forms. Based on that linguistic phenomenon, it can be argued, idiosyncrasy takes place in Madurese language. In other words, the productivity in shapes is not always in line with the productivity in meaning.

The result of the study shows the importance of the information pertaining to the verb formation of Madurese language. Not only linguists who may concerns about the issues risen, the public can also take advantage of research findings to make well informed of the verb formation of Madurese language. Furthermore, they can maintain healthy communication by using proper form of words choices and use.

\section{REFERENCES}

Azhar, I., N. (2018). Panorama Bhasa Madhura: Buku Panduan Mempelajari asal-usul, struktur, makna, gaya dan variasi bahasa Madura. Malang: Intelegensia Media.

Bolozky, S. (1982). Strategies of Modern Hebrew Verb Formation. Retrieved from: http://kb.osu.edu/dspace/bitstream/handle/1811/58646/HAR v6 069.pdf?sequence= 1 .

Carstairs-McCarthy, A. (2002). An Introduction to English morphology: Words and their structure. Edinburgh University Press. UK.

Davies, W., D. (2010). A grammar of madurese. New York: De Gruyter Mouton.

Fromkin, V., Rodman, R., \& Hyams, N. (2011). An introduction to language. Wadsworth Cengage Learning: Australia.United States.

Ghafur, A. (2008). Madurese and English Language. Retrieved from https://kampungtadris.wordpress.com/2008/10/31/madurese-and-englishlanguage/.

Jeoung. H. (2016). Voice and register differences in Madurese. Hsieh. H, (ed). The Proceedings of the 22nd Meeting of the Austronesian Formal Linguistics Association. Canberra: Asia-Pacific Linguistics.

Lieber, R. (2009). Introducing Morphology. Cambridge: Cambridge University Press. 
Nordquist, R. (2017). Affixation (words). Retrieved from: http://grammar.about.com/od/ab/g/Affixation.htm.

Wu, Z., \& Palmer, M. (1994). Verbs Semantics and Lexical Selection. Retrieved from: http://delivery.acm.org/10.1145/990000/981751/p133-

wu.pdf?ip $=114.125 .84 .217 \& \mathrm{id}=981751 \&$ acc $=$ OPEN\&key $=4 \mathrm{D} 4702 \mathrm{~B} 0 \mathrm{C} 3 \mathrm{E} 38 \mathrm{~B} 35 \% 2 \mathrm{E} 4 \mathrm{D}$ 4702B0C3E38B35\%2E4D4702B0C3E38B35\%2E6D218144511F3437\&CFID=885989674 \&CFTOKEN $=73740084 \& \quad \mathrm{acm} \quad=1483772270 \quad 685 \mathrm{f} 91 \mathrm{c} 046 \mathrm{~b} 9 \mathrm{cb} 4 \mathrm{bd044e} 4 \mathrm{a} 68 \mathrm{~d} 4548 \mathrm{c} 1$ 